${ }^{1}$ Social Determinants of Health Research Center, Research Institute for Prevention of Non-Communicable Diseases, Qazvin University of Medical

${ }^{2}$ Health Products Safety Research Center, Qazvin University of Medical Sciences, Qazvin, Iran

${ }^{3}$ Student Research Committee, Qazvin University of Medical Sciences, Qazvin, Iran

\title{
Applying the health belief model and behavior of diabetic patients: A systematic review and meta-analysis
}

\section{ABSTRACT}

The patient's belief and knowledge about his or her illness is the most important factor of disease control; the aim of present study is to perform a systematic review-based meta-analysis of health belief and its dimension's mean score in diabetic patients.

The present systematic review and meta-analysis was conducted in 2020. Data were gathered by searching the Google Scholar, Scopus, PubMed, Web of Science, and Science Direct databases from 2010 to 2020. Key words were "health belief", "HBM", "diabetic patients", "diabetes mellitus". To estimate the pooled score of health belief and its dimensions, the randomeffects meta-analysis was performed using STATA 15. The presence of heterogeneity across the studies was assessed with the 12 statistic. A forest plot was used to report the results.

The mean of health belief was $(3.422,95 \% \mathrm{Cl}: 3.128-$ -3.716) based on the fixed effect model and (3.422, 95\% Cl: 3.128-3.716) based on the random effect model, is the same. The strongest dimension is "perceived benefits" with an mean (3.8) and the weakest dimension is "perceived sensitivity" with an mean (3.0). Conclusions. Policymakers and decision makers in the field of hygiene and controlling non-communicable

Address for correspondence:

Aisa Maleki

Health Products Safety Research Center

Qazvin University of Medical Sciences

Qazvin, Iran

e-mail: aisamalekii@gmail.com

Clinical Diabetology 2021, 10; 2: 209-220

DOI: $10.5603 /$ DK.2021.0020

Received: 13.12 .2020 diseases should focus on the role of patients' awareness of their disease and try to improve it. In the meantime, the dimension of "perceived sensitivity" needs more attention. Strategies such as holding training classes and using technological infrastructure to promote this concept should be used. (Clin Diabetol 2021; 10; 2: 209-220)

Key words: health belief model, diabetic patients, systematic review, meta-analysis

\section{Introduction}

Chronic diseases are costly problems for health systems. According to the World Health Organization, the four most common chronic diseases are cardiovascular diseases, respiratory diseases, cancer, and diabetes [1]. Diabetes is a serious and long-term disease that refers to conditions in which the level of glucose in a person's blood increases and the body is unable to produce insulin or cannot use the insulin effectively [2]. The main types of diabetes include type1 diabetes, type 2 diabetes, gestational diabetes, and diabetes due to certain diseases [3]. Diabetes is a leading cause of complications such as kidney failure, myocardial infarction, blindness, and amputation of the lower limbs [4]. Diabetes and its complications often put a heavy burden on health systems and individuals. Global diabetes costs are projected to increase from $\$ 673$ billion to $\$ 802$ billion from 2015 to 2040 [5, 6]. In general, diabetic patients consume the largest amount of health care resources [1]. Achieving an efficient health system is realized when the gains are more than the resources spent and steps are taken to reduce the waste of resources [7]. On the other hand, people's lifestyles are 
directly related to daily behaviors and activities [8]. Self-care management as a routine lifetime behavior in diabetic patients plays a major role in the successful controlling of diabetes complications and preventing cost overruns [2]. Health-related behaviors as part of self-care management are determined by health and illness beliefs based on a person's knowledge of the disease. In other words, the concept of belief can lead to safety, improve health and consequently reduce costs in all aspects of health care [9]. Therefore, one of the most widespread concepts used in theoretical studies in behavior modification and knowledge is the health belief model [10]. About 422 million people worldwide suffer diabetes, especially in low- and middle-income countries. According to the World Health Organization statistics, the highest prevalence of diabetes (13.7\%) is related to the eastern Mediterranean; Southeast Asia and the United States are next [11]. The health belief model (HBM) is one of the most common patterns in health promotion programs and it explains why a person participates or does not participate in preventive health measures [12]. Adherence and compliance with diabetes control methods are directly related to a person's health belief and its dimensions [13]. This model includes the following dimensions:

- Perceived severity: Beliefs about the severity of a disease:

- Perceived susceptibility: Beliefs about the possibility of acquiring a chronic disease;

- Perceived barriers: Beliefs about barriers to performing a behavior and the negative aspects of adopting a health behavior;

- Perceived benefits: Beliefs about the positive aspects of adopting a health behavior [14].

A positive health belief about diabetes is expected to improve the patient's commitment to treatment, regular medication use, and timely action. Low health belief also makes this process difficult and hard to control [15]. Due to the high importance of diabetes control as a chronic and harmful disease and the great impact of health belief structures on this issue, many studies have been done in this field. For example, in a study by Amir R. Said and colleagues (2019) in Egypt, the test group, which received training in health belief structures, had a healthier lifestyle than the control group [16]. In a 2018 study by Barry W Rover et al. in Philadelphia, people with lower levels of health belief had lower drug compliance and self-control [17]. The results of a 2018 study by Razel Custodio et al. in the Philippines showed that health belief scores have improved in the diabetes care intervention group, which received educational text messages about health belief, which has increased [18]. The high number of diabetic patients and the costs imposed on health systems to alleviate its effects show the importance of paying attention to this chronic disease. So far, many policies have been developed in different countries to diagnose early and control different types of diabetes. Unfortunately, many of them have ignored the role of patient awareness and behavior. Given that the patient's belief and knowledge about his or her illness is more decisive than any other factors, health belief has been one of the most obvious and important concepts in the study of diabetic patients. The aim of the present study is to perform a systematic review of health belief status of diabetic patients, using the meta-analysis method.

\section{Methods}

\section{Design}

This systematic review and meta-analysis was conducted in 2020 in accordance with the guidelines of Preferred Reporting Items for Systematic Reviews and Meta-Analyses statement (PRISMA) [19].

\section{Search strategy}

Data were gathered by searching the Google Scholar, Scopus, PubMed, Web of Science, and Science Direct databases up to April 2020. To identify and cover more articles, a hand search of some credible key journals was also performed. The Boolean operators AND, $\mathrm{OR}$, and NOT were used to combine or limit search results (Appendix 1)

\section{Inclusion and exclusion criteria}

For the selection of articles related to the research area, the inclusion criteria were:

- Studies done in the field of health belief status in diabetic patients during the last 10 years;

- All sectional descriptive and analytical studies with different methodologies; and

- Only Persian and English studies. The exclusion criteria were:

- Studies in health belief status related to diseases other than diabetes;

- Health belief studies that do not provide the four main dimensions;

- Articles of health belief that do not report the mean and standard deviation; and

- Articles whose full text was not easily accessible.

\section{Review process}

The articles with the key words: "health belief", "HBM", "diabetic patients", "diabetes mellitus" in their titles and abstracts were selected. Then, duplicate publications were identified and removed from the review process. Then, inclusion and exclusion criteria were 


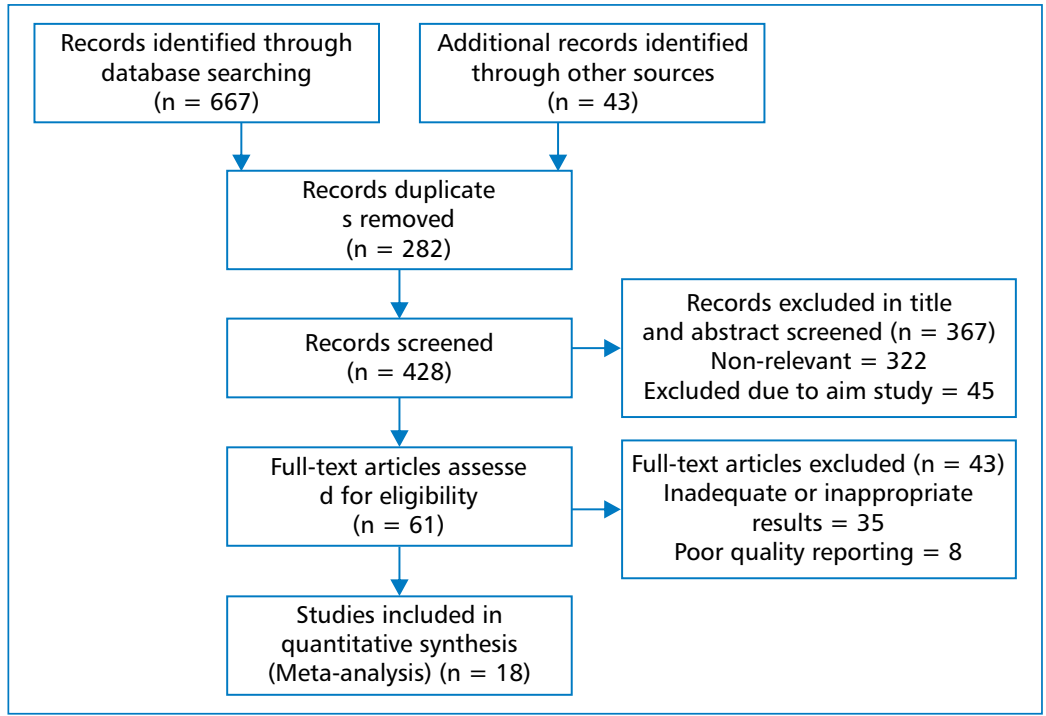

Figure 1. The flow diagram of the literature search

applied. Finally, a list of titles of all searched articles in the databases was prepared. A list of selected studies was screened to determine the most relevant ones, and the irrelevant articles were rejected. Evaluating and organizing the abstract titles as well as finding and removing the duplicate records were all done using resource management software (EndNote X6).

\section{Quality assessment and data extraction}

Two reviewers independently assessed the reporting quality of articles by STROBE (Strengthening the Reporting of Studies in Epidemiology Observational) checklist [20]. The checklist acquired 22 items in abstract, introduction, method, results and discussion sections. Evaluation process started and articles that did not report more than $50 \%$ of items in the checklist were excluded. After evaluating the quality, 18 articles were selected for data extraction. The required data including author/publication year, setting, sample size, tool, mean and standard deviation of health belief dimensions and total mean and standard deviation of health belief were extracted in the table.

\section{Data analysis}

To estimate the pooled score of health belief and its dimensions, the random-effects meta-analysis was performed using STATA 15 and results of the analysis were reported in $95 \%$ confidence interval. The probability of heterogeneity across the studies was assessed by the 12 statistic ( $12 \geq 50 \%$ indicate heterogeneity). For reporting the results, also forest plot was used. To identify the source of heterogeneity, a sensitivity analysis was done. Publication bias was assessed through the funnel plot and Excel 2010 was used to draw a graph. It is noteworthy that the score reported for health belief and its dimensions in all studies was not between 1 and 5 . Therefore, all the scores of the variables were normalized between 1 and 5 .

\section{Ethical approval}

The present study was approved by ethical committee of the Qazvin University of Medical Sciences (ethics code IR. QUMS. REC. 1399. 123).

\section{Result}

The database search identified 710 studies; 282 articles were rejected due to repetition. After screening the title and abstract, 367 studies were rejected; then 43 papers were rejected by screening the full text. Finally, 18 articles were selected which were fully consistent with the purposes of this study (Figure 1).

Table 1 presents the articles included in the metaanalysis based on features such as the year of publication, the context under study, sample size and type of questionnaire. In this table, the mean and standard deviation of the total score of health belief and its dimensions are displayed. As it is seen, in almost all studies mean of total health belief scores is around 3, that is, in the middle of the five-point Likert scale. The lowest $(2.43 \pm 0.98)$ and highest $(3.92 \pm 0.49)$ mean for health belief score have been reported in the studies of Jalilian et al. and Gatwood et al., respectively. The maximum mean reported in the studies was (), which was related to the perceived benefits; however, among all the studies, the perceived barriers had the lowest mean $(1.44 \pm 0.95)$. 
Table 1. Features of studies included in the meta-analysis

\begin{tabular}{|c|c|c|c|c|c|c|c|c|c|c|c|c|c|c|}
\hline NO. & Author, year & Setting & $\begin{array}{l}\text { Tool } \\
\text { type }\end{array}$ & Sample & $\begin{array}{l}\text { Mean } \\
\text { SU }\end{array}$ & $\begin{array}{l}\text { SD } \\
\text { SU }\end{array}$ & $\begin{array}{c}\text { Mean } \\
\text { SE }\end{array}$ & $\begin{array}{l}\text { SD } \\
\text { SE }\end{array}$ & $\begin{array}{c}\text { Mean } \\
\text { BE }\end{array}$ & $\begin{array}{l}\text { SD } \\
\text { BE }\end{array}$ & $\begin{array}{c}\text { Mean } \\
\text { BA }\end{array}$ & $\begin{array}{l}\text { SD } \\
\text { BA }\end{array}$ & $\begin{array}{c}\text { Total } \\
\text { Mean }\end{array}$ & $\begin{array}{l}\text { Total } \\
\text { SD }\end{array}$ \\
\hline$[21]$ & Kaya and Kitiş 2018 & Mersin, Turkey & DHBMS & 280 & 2.5 & 0.75 & 4 & 0.67 & 4 & 0.28 & 3.77 & 0.22 & 3.56 & 0.48 \\
\hline$[22]$ & Ağralı and Akyar 2014 & Ankara, Turkey & DHBMS & 70 & 2.9 & 0.4 & 3.9 & 0.5 & 3.6 & 0.4 & 3.1 & 0.5 & 3.3 & 0.45 \\
\hline$[23]$ & $\begin{array}{l}\text { Jalilian, Zinat Motlagh, } \\
\text { and Solhi } 2012\end{array}$ & Hamadan, Iran & DHBMS & 1400 & 2.35 & 1.04 & 1.77 & 0.86 & 2.19 & 1.1 & 3.44 & 0.91 & 2.43 & 0.98 \\
\hline$[24]$ & $\begin{array}{l}\text { Malekmahmoodi } \\
\text { et al. } 2019\end{array}$ & Kashan, Iran & EHBM & 320 & 3.36 & 0.69 & 4.27 & 0.67 & 2.98 & 0.63 & 4.16 & 0.77 & 3.69 & 0.69 \\
\hline$[25]$ & Borji et al. 2017 & Ilam, Iran & EHBM & 300 & 2.68 & 1.18 & 2.79 & 0.84 & 3.05 & 0.78 & 3.08 & 0.51 & 2.9 & 0.83 \\
\hline$[26]$ & $\begin{array}{l}\text { Farahani Dastjani } \\
\text { et al. } 2016\end{array}$ & Arak, Iran & EHBM & 366 & 3.27 & 0.92 & 2.54 & 0.32 & 4.3 & 0.62 & 2.68 & 0.87 & 3.2 & 0.68 \\
\hline$[27]$ & Rahimi et al. 2016 & $\begin{array}{l}\text { Kermanshah, } \\
\text { Iran }\end{array}$ & EHBM & 400 & 3.34 & 0.93 & 3.31 & 0.77 & 2.91 & 0.64 & 3.83 & 0.72 & 3.35 & 0.76 \\
\hline$[28]$ & $\begin{array}{l}\text { Morowatishaifabad } \\
\text { et al. } 2016\end{array}$ & Yazd, Iran & EHBM & 300 & 3.44 & 1.69 & 2.91 & 1.17 & 4.5 & 0.59 & 1.44 & 0.95 & 3.07 & 1.1 \\
\hline$[29]$ & $\begin{array}{l}\text { Vazini and Barati } \\
2014\end{array}$ & $\begin{array}{l}\text { Hamadan, } \\
\text { Iran }\end{array}$ & EHBM & 390 & 2.6 & 0.7 & 3.11 & 0.61 & 4.18 & 1.06 & 3.08 & 0.73 & 3.24 & 0.77 \\
\hline$[30]$ & $\begin{array}{l}\text { Gutierrez and Long } \\
2011\end{array}$ & $\begin{array}{c}\text { Philadelphia, } \\
\text { America }\end{array}$ & EHBM & 152 & 4.2 & 0.9 & 4.2 & 0.9 & 4.25 & 0.62 & 1.52 & 0.62 & 3.54 & 0.76 \\
\hline [31] & $\begin{array}{l}\text { Baghianimoghadam } \\
\text { et al. } 2010\end{array}$ & Yazd, Iran & EHBM & 111 & 4.07 & 0.62 & 3.73 & 0.62 & 3.7 & 0.51 & 3.53 & 0.77 & 3.75 & 0.63 \\
\hline$[32]$ & Dea 2019 & $\begin{array}{c}\text { Arba Minch, } \\
\text { Ethiopia }\end{array}$ & $\begin{array}{l}\text { HBM } \\
4 \mathrm{D}\end{array}$ & 595 & 3.75 & 0.64 & 2.74 & 0.95 & 4 & 0.65 & 3 & 0.76 & 3.37 & 0.75 \\
\hline [33] & Ishtaya et al. 2018 & $\begin{array}{l}\text { Nablus, } \\
\text { Palestine }\end{array}$ & $\begin{array}{l}\text { HBM } \\
4 \mathrm{D}\end{array}$ & 300 & 2.81 & 0.66 & 3.23 & 0.6 & 3.82 & 0.4 & 2.66 & 0.51 & 3.13 & 0.55 \\
\hline$[34]$ & Gatwood et al. 2016 & $\begin{array}{l}\text { Memphis, } \\
\text { USA }\end{array}$ & $\begin{array}{l}\text { HBM } \\
4 \mathrm{D}\end{array}$ & 24 & 3.7 & 0.57 & 4.3 & 0.44 & 3.9 & 0.34 & 3.8 & 0.63 & 3.92 & 0.49 \\
\hline [35] & Chao et al. 2012 & $\begin{array}{l}\text { Tainan, } \\
\text { Taiwan }\end{array}$ & $\begin{array}{l}\text { HBM } \\
4 \mathrm{D}\end{array}$ & 168 & 1.47 & 0.42 & 4.04 & 0.76 & 3.53 & 0.5 & 2.45 & 0.54 & 2.87 & 0.55 \\
\hline [36] & Park et al. 2018 & Korea & $\begin{array}{l}\text { HBM } \\
5 \mathrm{D}\end{array}$ & 237 & 3.72 & 0.67 & 3.68 & 0.65 & 3.97 & 0.57 & 3.25 & 0.66 & 3.65 & 0.63 \\
\hline [37] & Karimy et al. 2016 & $\begin{array}{l}\text { Zahedan, } \\
\text { Iran }\end{array}$ & $\begin{array}{l}\text { HBM } \\
5 \mathrm{D}\end{array}$ & 210 & 3.44 & 1.13 & 3.14 & 0.99 & 4.66 & 1.27 & 2.66 & 0.84 & 3.477 & 1.06 \\
\hline [38] & $\begin{array}{l}\text { Dehghani-Tafti } \\
\text { et al. } 2015\end{array}$ & Yazd, Iran & $\begin{array}{l}\text { HBM } \\
5 \mathrm{D}\end{array}$ & 110 & 2.66 & 0.59 & 4.65 & 0.31 & 4.36 & 0.51 & 3.34 & 0.47 & 3.75375 & 0.47425 \\
\hline
\end{tabular}

SU — perceived susceptibility; SE — perceived severity; BE — perceived benefits; BA — perceived barriers; Total — total health beliefs

The bar graph of the mean health belief and its dimensions is illustrated in Figure 2. As can be seen, the highest mean is for perceived benefits and the lowest is for perceived susceptibility.

Figure 3 shows the forest chart for the mean health beliefs. In this chart, first mean health belief has been calculated based on two methods, fixed effects $(3.422$, 95\% Cl: 3.128-3.716) and random effects (3.422, 95\% $\mathrm{Cl}$ : 3.128-3.716). Since the heterogeneity among the studies was zero (Heterogeneity Chi-squared $=5.19$, d.f. $=17, p=0.997$, l-squared $=0.0 \%$ ), the mean obtained from the two fixed and random methods is the same. As well as hypothesis mean health beliefs $=0)$ has been rejected $(z=22.84, p=0.000)$.

Results of meta-analysis on the mean of perceived susceptibility are seen in Figure 4. Here also, the pooled mean of the variable is estimated in two ways. Based on the fixed effects method, the pooled mean of this dimension was 2.964, (95\% Cl: 2.653-3.275), while in the method of random effects, he pooled mean of the perceived susceptibility 3.042 was calculated (95\% $\mathrm{Cl}$ : 2.650-3.434). There was a slight heterogeneity across the studies [heterogeneity chi-squared $=24.44$, (d.f. $=17) \mathrm{P}=0.108$, l-squared $=30.4 \%$ ]. The hypothesis 


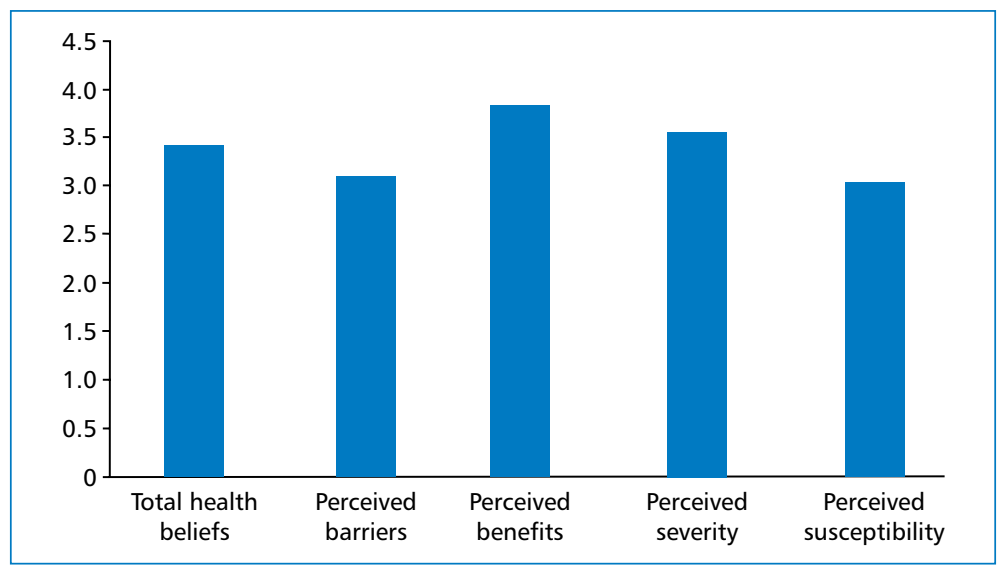

Figure 2. Pooled mean of health beliefs and its dimensions

\begin{tabular}{|llllll}
\hline Author & $\mathrm{Y}$ & & $\%$ \\
Weight \\
Kaya, et al
\end{tabular}

Figure 3. The health beliefs mean based on the random effect model

that the pooled mean equals to zero were also rejected $(z=18.68, p=0.000)$.

Results of pooling the mean of perceived severity have been shown in Figure 5. Based on the fixed effects method, the pooled mean of this dimension was 3.626, (95\% Cl: 3.361-3.892), while in the method of random effects, the pooled mean of the perceived severity 3.555 was calculated (95\% Cl: 3.14-3.97). There was a moderate heterogeneity across the studies [heterogeneity chi-squared $=35.50$, (d.f. $=17$ ) $\mathrm{P}=0.005$, l-squared $=52.1 \%]$. Also, the pooled mean of the perceived intensity was statistically significant $(z=26.77, p=0.000)$.

Figure 6 indicates the results of the pooled mean of perceived barriers have been shown in. Based on the fixed effects method, the pooled mean of this dimension was 3.26, (95\% Cl: 3.013-3.512), while in the method of random effects, the pooled mean of the perceived severity 3.12 was calculated $(95 \% \mathrm{Cl}$ : $2.787-$ 3.457). The heterogeneity among the studies was small, which was not statistically significant [heterogeneity Chi-squared $=24.83$, (d.f. $=17$ ), $P=0.099$, l-squared $=31.5 \%$ ]. Also, the pooled mean of the perceived barriers was statistically significant $(z=25.63, p=0.000)$.

Figure 7 displays the results of pooling the mean of perceived benefits. According to both methods, fixed and random effects, the pooled mean of this dimension was 3.83 , (95\% Cl: 3.600-4.075). The heterogeneity among the studies was zero [heterogeneity Chi-squared $=12.34$, (d.f. $=17$ ), $P=0.779$, l-squared $=0.0 \%$ ]. Also, the pooled mean of the perceived benefits was statistically significant $(z=31.66, P=0.000)$. 


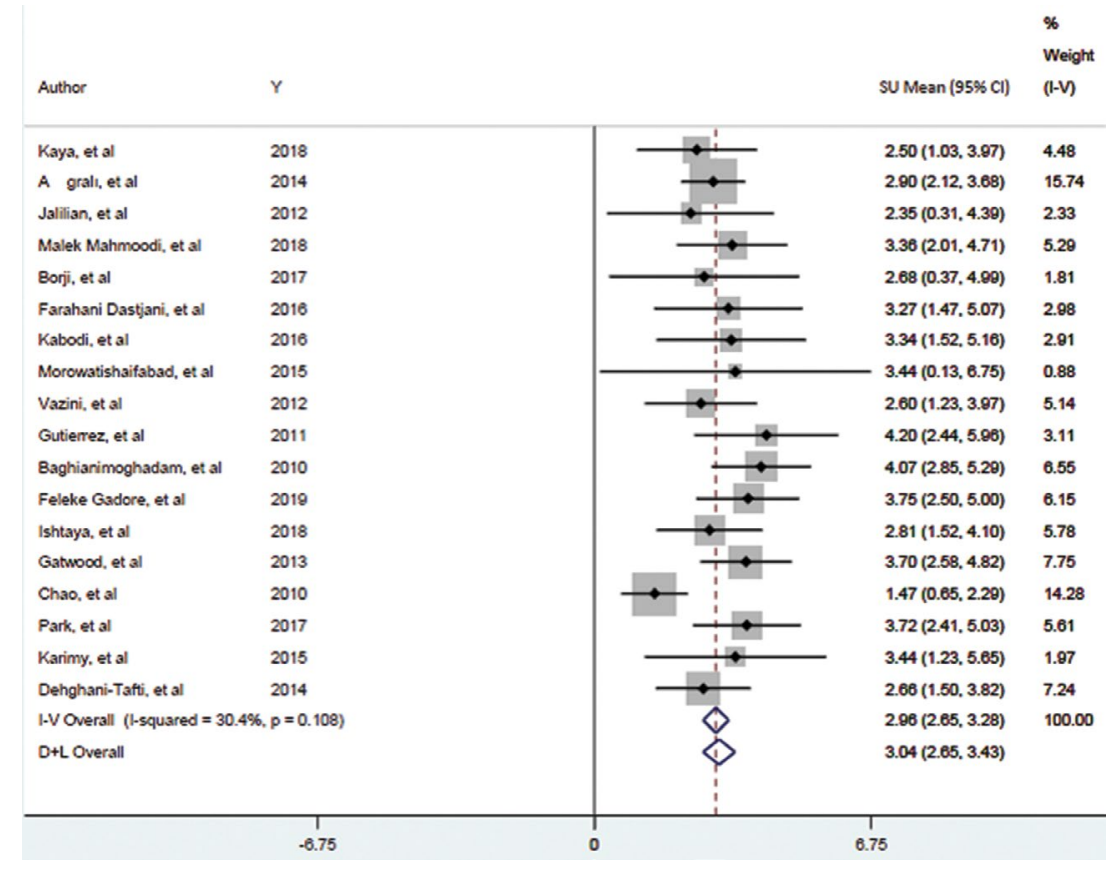

Figure 4. The perceived susceptibility mean based on the random effect model

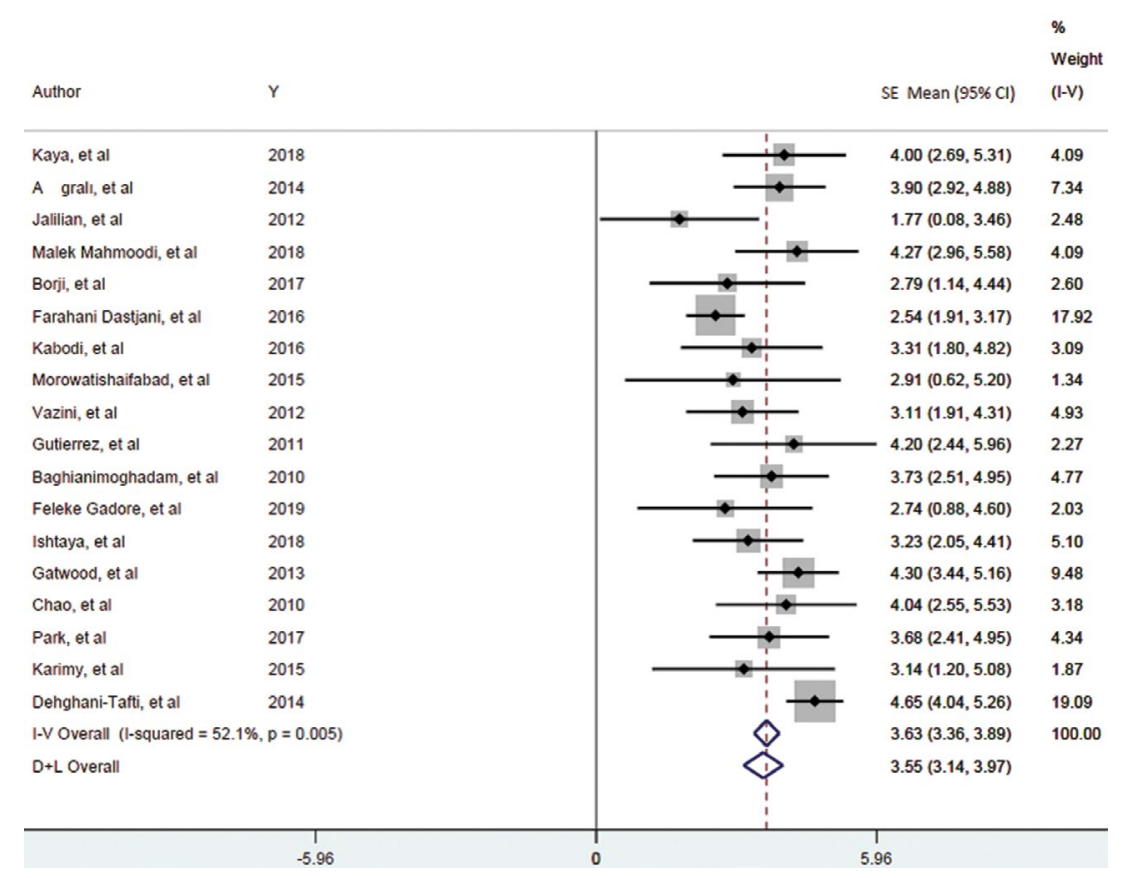

Figure 5. The perceived severity mean based on the random effect model

\section{Discussion}

In order to improve their health behavior, people must have strong health beliefs. That is, they should be sensitive to health risks, understand the severity of these risks, and know the benefits of improving behavior. The possibility of improving health behavior in a population group can be determined through the level of health belief and its dimensions. Differ- ent studies have reported different means for health belief and its dimensions. The aim of our study was to estimate a pooled mean of various studies results. For this purpose, a systematic review based meta-analysis of published studies was performed. Our findings showed that the highest mean of health belief (3.92) is related to the Gatwood study in the United States according to the HBM-4D questionnaire. Also, the lowest 


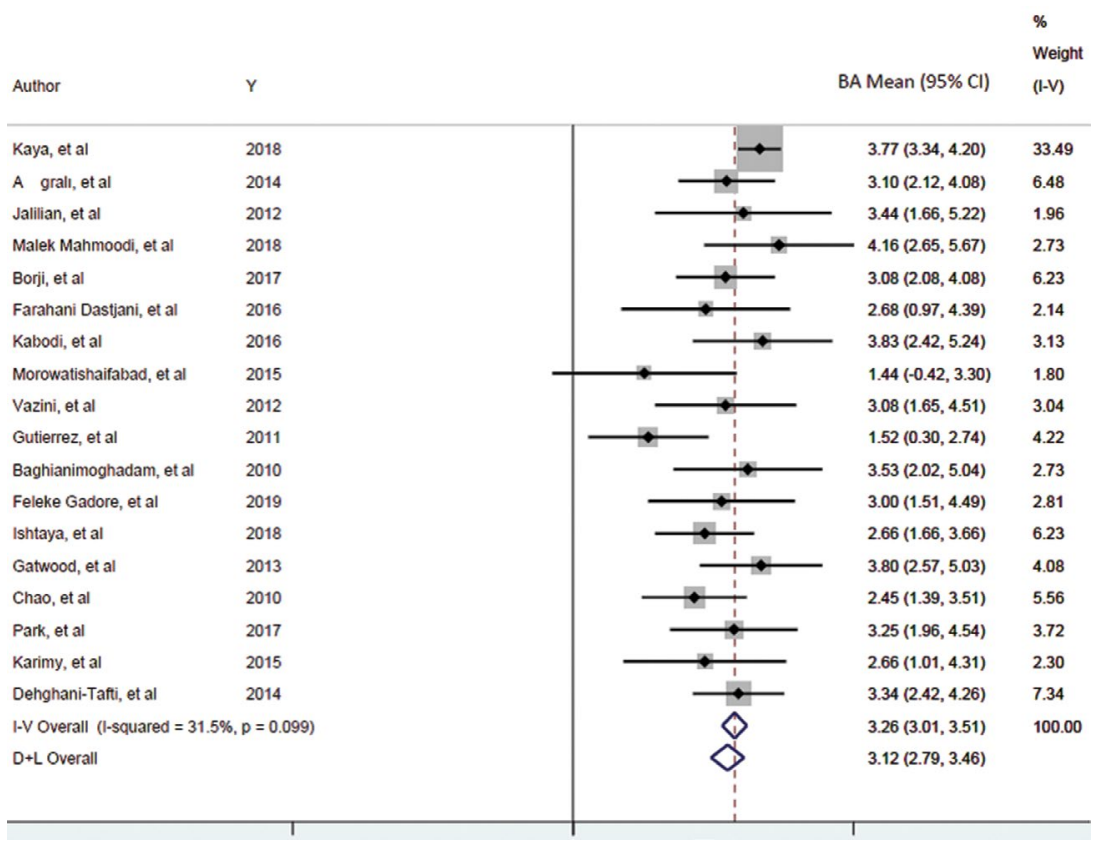

Figure 6. The perceived barriers mean based on the random effect model

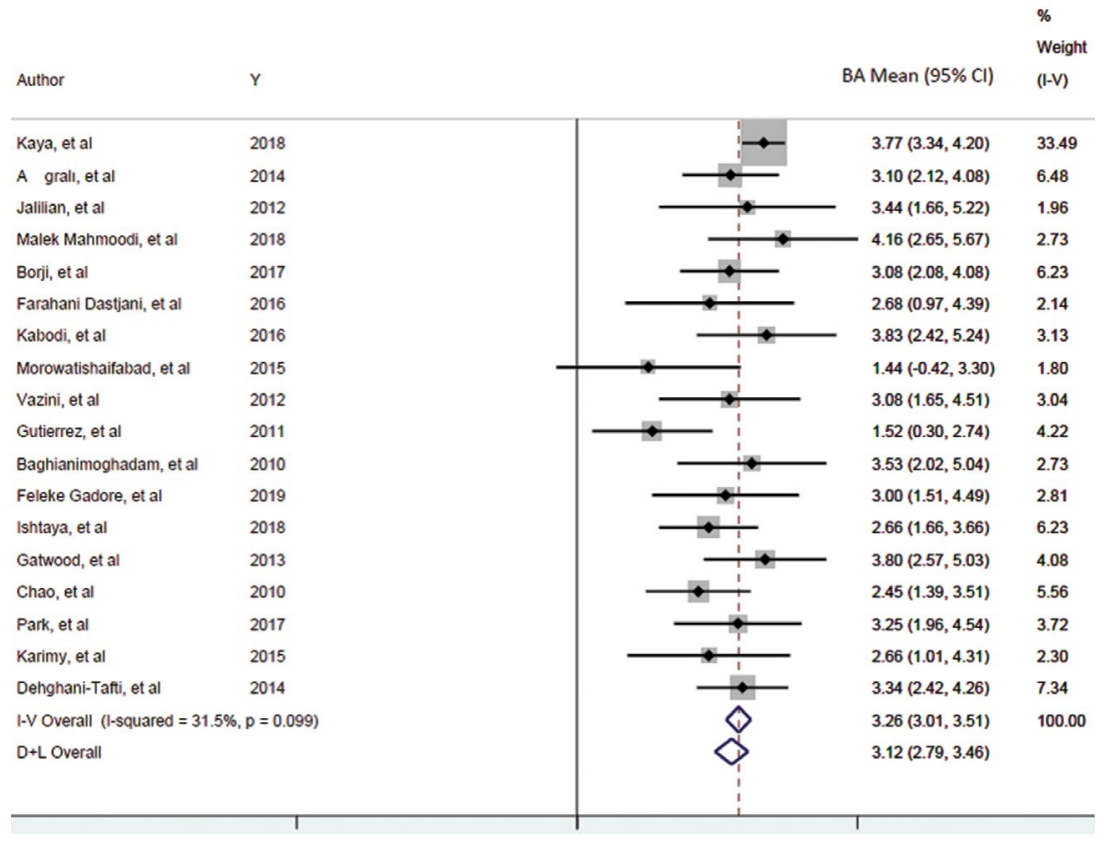

Figure 7. The perceived benefits mean based on the random effect model

mean of health belief (2.43) is related to Jalilian study in Iran using the DHBMS questionnaire. The results of meta-analysis displayed that the pooled mean of health belief in this study is (3.42), the highest mean (3.83) was related to perceived benefits and the lowest mean (2.96) was also obtained for perceived susceptibility. Contrary to Saeedinia's study, the results of our study showed that the perceived benefits in the reviewed studies were favorable. This discrepancy may be due to the ineffective educational interventions related to understanding the dimensions of health belief and people's lack of understanding of the positive aspects of adopting a healthy behavior[39]. Compatible with our findings, the results of Tavakoli study, reports a desirable level of perceived benefits. Education-based health belief model, reproduction of relevant brochures and 
books, holding face-to-face classes, creating personal and social motivation and increasing self-confidence have had an important impact on this dimension and have stabilized its desired position [40]. Farmhand's study is in line with this study. Lectures, question and answer sessions, group discussions, educational slides, and presentation of relevant pamphlets have increased people's understanding of "perceived benefits" [41]. "Perceived sensitivity" has a low score, which is not in line with Dadkhah Tehrani's study; This discrepancy can be related to training sessions to raise awareness and full knowledge of symptoms, underlying factors, risk factors, methods of prevention, treatment and control of diabetes and healthy lifestyle methods in Dadkhah Tehrani's study and higher score of this dimension [42]. Mohebbi's study, because of sharing information about diabetes and using a mobile phone as a learning tool, has a favorable perceived sensitivity and it is inconsistent with the present study [43]. According to the results, the "perceived severity" dimension is relatively favorable and it is consistent with the study of Alatawi and Aris. Relatively good knowledge of patients about the type, timing, and conditions of diabetes testing and the implementation of self-management programs for greater effectiveness of care programs and increased quality of life, can be reasons for this desirable level $[44,45]$. The acceptable level of "perceived barriers" in this study is consistent with the Khiyali's study. Increased levels of awareness and knowledge about diabetes, its causes and symptoms, control methods, its negative impact and holding training courses based on the health belief model, are the reasons for achieving of this acceptable level [46]. Mohammadi's study is not consistent with our study in terms of "perceived barriers" and health belief levels. Low self-efficacy and negative perceptions of health belief's dimensions, are some of the reasons for this inconsistency [47]. Health belief in the present study has a favorable level that is consistent with the study of Porgholmi. A controlled level of fear can help the patient make better decisions about diabetes and increase adherence to treatment and health belief [48]. The level of health belief in Fani's study is also consistent with the present study. In this study, education has been used as a lever to improve the health belief's dimensions and increase the patient's belief and adherence to treatment and medication, diet and diabetes control [49]. On the other hand, the study of Zamani is not in line with the present study due to the low effect of education, lack of awareness of patients about diabetes and the importance and manner of control actions [50]. Improving the level of health belief as a diabetes controller should be considered by health policymakers and non-communicable disease decision makers. Currently, there are various programs in most countries for early detection and control of the damage of this disease; screening is one of these programs that cost a lot. Controlling diabetes is a progressive problem requires a long-term, low-cost solution; so find a solution that can be less expensive, more productive and most importantly, patient-centered in a long time, requires more effort and focus.

\section{Conclusion}

Knowing the accurate level of health belief can be a worthy guide to predict the effectiveness of health interventions in the community. The results of the meta-analysis showed that health belief and its dimensions in the reviewed studies are almost around the mean level. That is, the health beliefs of the populations studied in the papers included in the meta-analysis were moderate. Widespread informing through the mass media, improving the level of intellectual maturity of the society, surveying and considering diabetes as a global issue have led to a significant increase in positive behaviors in patients. Therefore, maintaining the level of the dimension of "perceived benefits" and increasing it more, is an important thing that can be done by holding cultural, social and environmental training courses such as courses to increase self-efficacy for young and old. Low levels of "perceived sensitivity" can be due to demographic factors such as occupation and gender, chronic and non-communicable diabetes, as well as its genetic status in some cases. Paying attention to the incidence of diabetes in the family, the constant examination of the health status by the doctor in people with risk factors, more social attention to this disease, increases the sensitivity of people in society about this issue. The outcome of the dimension's level reflects the relatively favorable state of health belief. There are various strategies to develop this issue, such as: holding face-to-face training classes in urban health centers, producing related pamphlets, holding online classes for quick response to searchers, more media advertising, producing informative mobile applications, using robots and modern technologies, establishing special diabetes associations in schools and universities and relevant organizations. Improving the level of health belief leads to prevention and control of diabetes. Preventing disease in the first place can help to keep society healthy, and in the later stages can reduce costs and pressures on the health system, improve the quality of life, increase life expectancy and improve health indicators. Increasing people's awareness of their illness, adherence to treatment, 
self-efficacy, healthy lifestyle, mental and social health are some of the strategies that can play an important role in maintaining the health of diabetic people. The present study has some limitations, such as

- Lack of access to some databases;

- Lack of full text of some relevant articles;

- Lack of review of studies related to the health of others disease's beliefs.

\section{Conflict of interest}

Not applicable.

\section{REFERENCES}

1. Coronado-Vázquez V, Gómez-Salgado J, Monteros JC, et al. Equidad y autonomía del paciente en las estrategias de atención a personas con enfermedades crónicas en los servicios de salud de España. Gaceta Sanitaria. 2019; 33(6): 554-562, doi: 10.1016/j. gaceta.2018.05.008.

2. IDF. Diabetes Atlas: international diabetes federation; 2019 [9th edition].

3. Cefalu WT, Berg EG, Saraco M, et al. Classification and Diagnosis of Diabetes: Standards of Medical Care in Diabetes-2019. Diabetes Care. 2019; 42: S13-S28.

4. Bukhsh A, Nawaz MS, Ahmed HS, et al. A randomized controlled study to evaluate the effect of pharmacist-led educational intervention on glycemic control, self-care activities and disease knowledge among type 2 diabetes patients: A consort compliant study protocol. Medicine (Baltimore). 2018; 97(12): e9847, doi: 10.1097/MD.0000000000009847, indexed in Pubmed: 29561461.

5. Gettings JV, O'Connor R, O'Doherty J, et al. A snapshot of type two diabetes mellitus management in general practice prior to the introduction of diabetes Cycle of Care. Ir J Med Sci. 2018; 187(4): 953-957, doi: 10.1007/s11845-018-1754-9, indexed in Pubmed: 29417379

6. Kim W, Choy YS, Lee SAh, et al. Implementation of the Chronic Disease Care System and its association with health care costs and continuity of care in Korean adults with type 2 diabetes mellitus. BMC Health Serv Res. 2018; 18(1): 991, doi: 10.1186/ s12913-018-3806-2, indexed in Pubmed: 30577787.

7. Do medical records outsourcing affect insurance deductions? An Interrupted time series in Qazvin's trauma center. Journal of Surgery and trauma. 2019; 7(4): 152-160, doi: 10.32592/ jsurgery.2019.7.4.105

8. Ardebili EH, Barkati H, Omrani A, et al. Relationship between life style-related factors with cardiac ischemia among inpatients: A case-control study. journal of Health management and informatics. Journal of Health Management and Informatics. 2015; 1(2): 1-4.

9. Khosravizadeh O, Mohseni M, Baghian N, et al. Front-line staff's perspective on patient safety culture in Iranian medical centers: A systematic review and meta-analysis. International Journal of Risk \& Safety in Medicine. 2020; 31(4): 193-207, doi: 10.3233/ jrs-191021.

10. Antwi J, Lavin R, Sullivan S, et al. Perception of and risk factors for type 2 diabetes among students attending an upstate New York college: a pilot study. Diabetol Metab Syndr. 2020; 12: 25, doi: 10.1186/s13098-020-00535-1, indexed in Pubmed: 32256715.

11. Reports WHO. Available online: www.who.int/publications-detail/ global-report-on-diabetes,2020. [Last accessed: 28.12.2020]. reports WHO https://www who int/publications-detail/globalreport. ; 2020: 2020.

12. Luquis R, Kensinger W. Applying the Health Belief Model to assess prevention services among young adults. International Journal of Health Promotion and Education. 2018; 57(1): 37-47, doi: 10.1080/14635240.2018.1549958.

13. Mahmoud NM, Mohammed Y, Essa RM, et al. The relationship between health belief model and compliance with therapeutic regimen among diabetic pregnant women. International Journal For Research In Health Sciences And Nursing. 2018; 4(2): 40-63.

14. Wilcox K. Assessing type 2 diabetes risk perception among college students and creating health education tools using the health belief model. niversity Honors College, Middle Tennessee State University 2018.

15. Kaya ŞŞ, Kitiş Y. Elderly diabetes patients' health beliefs about care and treatment for diabetes. Journal of Human Sciences. 2018; 15(1): 51, doi: 10.14687/jhs.v15i1.4903.

16. Amira S, Fatma A. Effect of the Educational Package Based on Health Belief Model Regarding Lifestyle among Women with Gestational Diabetes Mellitus. International Journal of, 2019. Nursing Science. 2019; 9(2): 41-52.

17. Rovner BW, Casten RJ. Health beliefs and medication adherence in black patients with diabetes and mild cognitive impairment. Am J Geriatr Psychiatry. 2018; 26(7): 812-816, doi: 10.1016/j. jagp.2018.03.012, indexed in Pubmed: 29673896.

18. Custodio R, Victorino J, Estuar MJ. The efficacy of an EMRenabled text messaging system to the expanded health beliefs, diabetes care profile and $\mathrm{HbA1c}$ of diabetes mellitus patients. Procedia Computer Science. 2018; 138: 143-152, doi: 10.1016/j. procs.2018.10.021.

19. Liberati A, Altman DG, Tetzlaff J, et al. The PRISMA statement for reporting systematic reviews and meta-analyses of studies that evaluate health care interventions: explanation and elaboration. J Clin Epidemiol. 2009; 62(10): e1-34, doi: 10.1016/j. jclinepi.2009.06.006, indexed in Pubmed: 19631507.

20. Elm Ev, Altman D, Egger M, et al. The Strengthening the Reporting of Observational Studies in Epidemiology (STROBE) Statement: Guidelines for reporting observational studies. International Journal of Surgery. 2014; 12(12): 1495-1499, doi: 10.1016/j. ijsu.2014.07.013.

21. Şermet ŞŞ, Kitiş Y. Elderly diabetes patients' health beliefs about care and treatment for diabetes. Journal of Human Sciences. 2018; 15: 51-61.

22. Ağralı H, Akyar I. Older diabetic patients' attitudes and beliefs about health and illness. J Clin Nurs. 2014; 23(21-22): 3077-3086, doi: 10.1111/jocn.12540, indexed in Pubmed: 24479732.

23. Jalilian F. Zinat Motlagh F, Solhi M. Effectiveness of education program on increasing self management among patients with type II diabetes. Scientific Journal of Ilam University of Medical Sciences. 2012; 20(1): 26-34

24. Malekmahmoodi M, Shamsi M, Roozbahani N, et al. Effective factors on oral and dental health of patients with diabetes mellitus type 2 based on the health belief model. Journal of Education and Community Health. 2019; 6(1): 49-54, doi: 10.29252/jech.6.1.49.

25. Borji M, Sharifi A, Molavi R, et al. Insulin resistance beliefs in patients with type II diabetes according to the health belief model. Bioscience Biotechnology Research Communications. 2017; 10(2): 187-191, doi: 10.21786/bbrc/10.2/33.

26. Farahani $\mathrm{Da}$, Shamsi $\mathrm{M}$, Khorsandi $\mathrm{M}$, et al. To study the factors affecting medication adherence in diabetic patients based on health belief model in Arak, 2014. Journal of Arak University of Medical Sciences. 2016; 19(2): 49-58.

27. Rahimi M, Niromand $E$, Ajami $E$, et al. Belifs on insulin injection non-adherence among type 2 diabetic patients: assessmentbased on health belief model. Iranian Journal of Diabetes and Metabolism. 2016; 15(2): 110-9.

28. Morowatishaifabad M, Khajeh Z, Enjezab B, et al. Factors associated with preventive behaviors of candida albicans vaginal infection in women with diabetes, according to the health belief model in Yazd in 2013. Tolooebehdasht. 2016; 15(4): 77-90.

29. Vazini $H$, Barati $M$. The health belief model and self-care behaviors among type 2 diabetic patients. Iranian Journal of Diabetes and Obesity. 2014; 6(3): 107-113. 
30. Gutierrez J, Long JA. Reliability and validity of diabetes specific Health Beliefs Model scales in patients with diabetes and serious mental illness. Diabetes Res Clin Pract. 2011; 92(3): 342-347, doi: 10.1016/j.diabres.2011.02.018, indexed in Pubmed: 21411173.

31. Baghianimoghadam MH, Hadavand Khani M, Mohammadi SM. Status of walking behavior in patients with type 2 diabetes in Yazd based on health belief model. J Health Syst Res. 2010; 6(3): 425-435.

32. Dea YC. Predictors of diabetes self-care practice and associated factors among patient on follow up at hadiya zone, health institutions southern ethiopia, using health belief model, crosssectional study design. EC Endocrinology and Metabolic Research. 2019; 4: 1-17.

33. Ishtaya GA, Anabtawi YM, Zyoud SH, et al. Osteoporosis knowledge and beliefs in diabetic patients: a cross sectional study from Palestine. BMC Musculoskelet Disord. 2018; 19(1): 43, doi: 10.1186/s12891-018-1961-6, indexed in Pubmed: 29415696.

34. Gatwood J, Balkrishnan R, Erickson SR, et al. The impact of tailored text messages on health beliefs and medication adherence in adults with diabetes: A randomized pilot study. Res Social Adm Pharm. 2016; 12(1): 130-140, doi: 10.1016/j.sapharm.2015.04.007, indexed in Pubmed: 25980582.

35. Chao H, Lao I, Hao L, et al. Association of body image and health beliefs with health behaviors in patients with diabetes: a cross-sectional study. Diabetes Educ. 2012; 38(5): 705-714, doi: 10.1177/0145721712452796, indexed in Pubmed: 22814357.

36. Park S, Lee JL, In Sun J, et al. Knowledge and health beliefs about gestational diabetes and healthy pregnancy's breastfeeding intention. J Clin Nurs. 2018; 27(21-22): 4058-4065, doi: 10.1111/ jocn.14539, indexed in Pubmed: 29776004.

37. Karimy M, Araban M, Zareban I, et al. Determinants of adherence to self-care behavior among women with type 2 diabetes: an explanation based on health belief model. Med J Islam Repub Iran. 2016; 30: 368, indexed in Pubmed: 27493912.

38. Dehghani-Tafti A, Mazloomy Mahmoodabad SS, Morowatisharifabad MA, et al. Determinants of self-care in diabetic patients based on health belief model. Glob J Health Sci. 2015; 7(5): 33-42, doi: 10.5539/gjhs.v7n5p33, indexed in Pubmed: 26156902.

39. Saedinia A, Jahani Y, Iranpour A, et al. The effect of educational intervention based on the health belief model on diabetes screening behavior in over 30 years old men in Shahr-e-Babak. Health and Development Journal. 2018; 7(1): 89-97.

40. Tavakkoli R, Mahmoodi M, Attarian S. Study the effect of educational intervention based on the health belief model (HBM) on quality of life among women with gestational diabetes. Journal of Research in Medical and Dental Science. 2018; 6(2): 245-252.
41. Farahmand Z, Shojaeizadeh D, Tol A, et al. The impact of an educational program based on the health belief model on diabetic foot care in type-2 diabetic patients. Journal of School of Public Health and Institute of Public Health Research. 2017; 15(2): 171-184.

42. Dadkhah TB, Tavakoli R, Jazayeri SA, et al. The effect of an educational intervention based on health belief model on nutritional behaviors in type 2 diabetics. Military Caring Sciences. 2019; 5(4): 303-311, doi: 10.29252/mcs.5.4.303.

43. Mohebbi B, Tol A, Sadeghi R, et al. Self-management Intervention Program Based on the Health Belief Model (HBM) among Women with Gestational Diabetes Mellitus: A Quazi-Experimental Study. Arch Iran Med. 2019; 22(4): 168-173, indexed in Pubmed: 31126174.

44. Alatawi YM, Kavookjian J, Ekong G, et al. The association between health beliefs and medication adherence among patients with type 2 diabetes. Res Social Adm Pharm. 2016; 12(6): 914-925, doi: 10.1016/j.sapharm.2015.11.006, indexed in Pubmed: 26706405.

45. Aris A, Blake $H$, Adams $G$. Health beliefs predict self-care practices and glycaemic control in Malaysian patients with insulin-treated diabetes: a longtitudal study. Malaysian Journal of Public Health Medicine. 2017; 17(2).

46. Khiyali Z, Manoochri M, Babaei Heydarabadi A, et al. Educational intervention on preventive behaviors on gestational diabetes in pregnant women: application of health belief model. International Journal of Pediatrics. 2017; 5(5): 4821-31.

47. Mohammadi S, Karim NA, Talib RA, et al. The impact of selfefficacy education based on the health belief model in Iranian patients with type 2 diabetes: a randomised controlled intervention study. Asia Pac J Clin Nutr. 2018; 27(3): 546-555, doi: 10.6133/ apjcn.072017.07, indexed in Pubmed: 29737801.

48. Porgholmi M, Farmanbar $R$, Kasmaei $P$, et al. The effect of training program based on health belief model developed by the fear of self-care behavior and hba1c levels in patients with type 2 diabetes. ranian Journal of Health Education and Health Promotion. 2017; 5(1): 65-72, doi: 10.18869/acadpub. ihepsaj.5.1.65.

49. Fani N, Mohebbi B, Sadeghi R, et al. Assessing the effect of educational intervention on promoting nutrition adherence among patients with type 2 diabetes referee to South Health Center of Tehran University of Medical Sciences: application of health belief model. Iranian Journal of Diabetes and Metabolism. 2018; 17(1): 13-22.

50. Zamani N, Ahmadi Ta, Khanjani N, et al. The effect of educational intervention based on the health belief model on medication adherence among patients with diabetes referred to a diabetes center in Zarand, Kerman. Health and Development Journal. 2017: 6(2): 97-109. 


\section{Appendix 1}

\section{Prisma 2009 checklist}

\begin{tabular}{|c|c|c|c|}
\hline Section/topic & \# & Checklist item & Reported on page \# \\
\hline \multicolumn{4}{|l|}{ TITLE } \\
\hline Title & 1 & Identify the report as a systematic review, meta-analysis, or both. & Page 1 \\
\hline \multicolumn{4}{|l|}{ ABSTRACT } \\
\hline Structured summary & 2 & $\begin{array}{l}\text { Provide a structured summary including, as applicable: background; } \\
\text { objectives; data sources; study eligibility criteria, participants, and in- } \\
\text { terventions; study appraisal and synthesis methods; results; } \\
\text { limitations; conclusions and implications of key findings; } \\
\text { systematic review registration number. }\end{array}$ & Page 2 \\
\hline \multicolumn{4}{|l|}{ INTRODUCTION } \\
\hline Rationale & 3 & $\begin{array}{l}\text { Describe the rationale for the review in the context of what is already } \\
\text { known. }\end{array}$ & Introduction, last paragraph \\
\hline Objectives & 4 & $\begin{array}{l}\text { Provide an explicit statement of questions being addressed with } \\
\text { reference to participants, interventions, comparisons, outcomes, } \\
\text { and study design (PICOS). }\end{array}$ & $\mathrm{N} / \mathrm{A}$ \\
\hline \multicolumn{4}{|l|}{ METHODS } \\
\hline $\begin{array}{l}\text { Protocol and registra- } \\
\text { tion }\end{array}$ & 5 & $\begin{array}{l}\text { Indicate if a review protocol exists, if and where it can be accessed } \\
\text { (e.g., Web address), and, if available, provide registration information } \\
\text { including registration number. }\end{array}$ & $\begin{array}{l}\text { Methods, Paragraph } 2 \text { and } \\
\text { Appendix (page 9) }\end{array}$ \\
\hline Eligibility criteria & 6 & $\begin{array}{l}\text { Specify study characteristics (e.g., PICOS, length of follow-up) and } \\
\text { report characteristics (e.g., years considered, language, publication } \\
\text { status) used as criteria for eligibility, giving rationale. }\end{array}$ & Methods, Paragraph 2 and 3 \\
\hline Information sources & 7 & $\begin{array}{l}\text { Describe all information sources (e.g., databases with dates of cover- } \\
\text { age, contact with study authors to identify additional studies) in the } \\
\text { search and date last searched. }\end{array}$ & Methods, Paragraph 2 \\
\hline Search & 8 & $\begin{array}{l}\text { Present full electronic search strategy for at least one database, } \\
\text { including any limits used, such that it could be repeated. }\end{array}$ & Appendix (page 9) \\
\hline Study selection & 9 & $\begin{array}{l}\text { State the process for selecting studies (i.e., screening, eligibility, } \\
\text { included in systematic review, and, if applicable, included in the } \\
\text { meta-analysis). }\end{array}$ & Methods, Paragraph 4 and 5 \\
\hline $\begin{array}{l}\text { Data collection } \\
\text { process }\end{array}$ & 10 & $\begin{array}{l}\text { Describe method of data extraction from reports (e.g., piloted forms, } \\
\text { independently, in duplicate) and any processes for obtaining and con- } \\
\text { firming data from investigators. }\end{array}$ & Methods, Paragraph 4 and 5 \\
\hline Data items & 11 & $\begin{array}{l}\text { List and define all variables for which data were sought (e.g., PICOS, } \\
\text { funding sources) and any assumptions and simplifications made. }\end{array}$ & Methods, Paragraph 4 \\
\hline $\begin{array}{l}\text { Risk of bias in indi- } \\
\text { vidual studies }\end{array}$ & 12 & $\begin{array}{l}\text { Describe methods used for assessing risk of bias of individual studies } \\
\text { (including specification of whether this was done at the study or } \\
\text { outcome level), and how this information is to be used in any data } \\
\text { synthesis. }\end{array}$ & Methods, Paragraph 6 \\
\hline Summary measures & 13 & $\begin{array}{l}\text { State the principal summary measures (e.g., risk ratio, difference in } \\
\text { means). }\end{array}$ & Methods, Paragraph 6 \\
\hline Synthesis of results & 14 & $\begin{array}{l}\text { Describe the methods of handling data and combining results of stud- } \\
\text { ies, if done, including measures of consistency (e.g., 12) for each meta- } \\
\text { analysis. }\end{array}$ & Methods, Paragraph 6 \\
\hline
\end{tabular}




\section{Appendix 1}

\section{Prisma 2009 checklist}

\begin{tabular}{|c|c|c|c|}
\hline Section/topic & $\#$ & Checklist item & Reported on page \# \\
\hline $\begin{array}{l}\text { Risk of bias } \\
\text { across studies }\end{array}$ & 15 & $\begin{array}{l}\text { Specify any assessment of risk of bias that may affect the cumulative } \\
\text { evidence (e.g., publication bias, selective reporting within studies). }\end{array}$ & Methods, Paragraph 6 \\
\hline $\begin{array}{l}\text { Additional } \\
\text { analyses }\end{array}$ & 16 & $\begin{array}{l}\text { Describe methods of additional analyses (e.g., sensitivity or subgroup } \\
\text { analyses, meta-regression), if done, indicating which were pre-speci- } \\
\text { fied. }\end{array}$ & Methods, Paragraph 6 \\
\hline \multicolumn{4}{|l|}{ RESULTS } \\
\hline Study selection & 17 & $\begin{array}{l}\text { Give numbers of studies screened, assessed for eligibility, and included } \\
\text { in the review, with reasons for exclusions at each stage, ideally with a } \\
\text { flow diagram. }\end{array}$ & $\begin{array}{l}\text { Results, paragraph } 1 \\
\text { (figure1) }\end{array}$ \\
\hline Study characteristics & 18 & $\begin{array}{l}\text { For each study, present characteristics for which data were extracted } \\
\text { (e.g., study size, PICOS, follow-up period) and provide the citations. }\end{array}$ & Results, paragraph2 (table1) \\
\hline $\begin{array}{l}\text { Risk of bias } \\
\text { within studies }\end{array}$ & 19 & $\begin{array}{l}\text { Present data on risk of bias of each study and, if available, any out- } \\
\text { come level assessment (see item 12). }\end{array}$ & N/A \\
\hline $\begin{array}{l}\text { Results of individual } \\
\text { studies }\end{array}$ & 20 & $\begin{array}{l}\text { For all outcomes considered (benefits or harms), present, for each } \\
\text { study: (a) simple summary data for each intervention group (b) effect } \\
\text { estimates and confidence intervals, ideally with a forest plot. }\end{array}$ & $\mathrm{N} / \mathrm{A}$ \\
\hline Synthesis of results & 21 & $\begin{array}{l}\text { Present results of each meta-analysis done, including confidence inter- } \\
\text { vals and measures of consistency. }\end{array}$ & Results, paragraph3-8 \\
\hline $\begin{array}{l}\text { Risk of bias across } \\
\text { studies }\end{array}$ & 22 & $\begin{array}{l}\text { Present results of any assessment of risk of bias across studies (see } \\
\text { Item 15). }\end{array}$ & $\mathrm{N} / \mathrm{A}$ \\
\hline Additional analysis & 23 & $\begin{array}{l}\text { Give results of additional analyses, if done (e.g., sensitivity or subgroup } \\
\text { analyses, meta-regression [see Item 16]). }\end{array}$ & $\mathrm{N} / \mathrm{A}$ \\
\hline \multicolumn{4}{|l|}{ DISCUSSION } \\
\hline $\begin{array}{l}\text { Summary } \\
\text { of evidence }\end{array}$ & 24 & $\begin{array}{l}\text { Summarize the main findings including the strength of evidence for } \\
\text { each main outcome; consider their relevance to key groups (e.g., } \\
\text { healthcare providers, users, and policy makers). }\end{array}$ & $\begin{array}{l}\text { Discussion, paragraph } 1 \text { - last } \\
\text { one }\end{array}$ \\
\hline Limitations & 25 & $\begin{array}{l}\text { Discuss limitations at study and outcome level (e.g., risk of bias), and } \\
\text { at review-level (e.g., incomplete retrieval of identified research, report- } \\
\text { ing bias). }\end{array}$ & Conclusion, last paragraph \\
\hline Conclusions & 26 & $\begin{array}{l}\text { Provide a general interpretation of the results in the context of other } \\
\text { evidence, and implications for future research. }\end{array}$ & conclusion paragraph $1 \& 2$ \\
\hline \multicolumn{4}{|l|}{ FUNDING } \\
\hline Funding & 27 & $\begin{array}{l}\text { Describe sources of funding for the systematic review and other sup- } \\
\text { port (e.g., supply of data); role of funders for the systematic review. }\end{array}$ & Page 10 \\
\hline
\end{tabular}

Moher D, Liberati A, Tetzlaff J, Altman DG, The PRISMA Group (2009). Preferred Reporting Items for Systematic Reviews and Meta-Analyses: The PRISMA Statement. PLoS Med 6(7): e1000097. doi:10.1371/journal.pmed1000097 